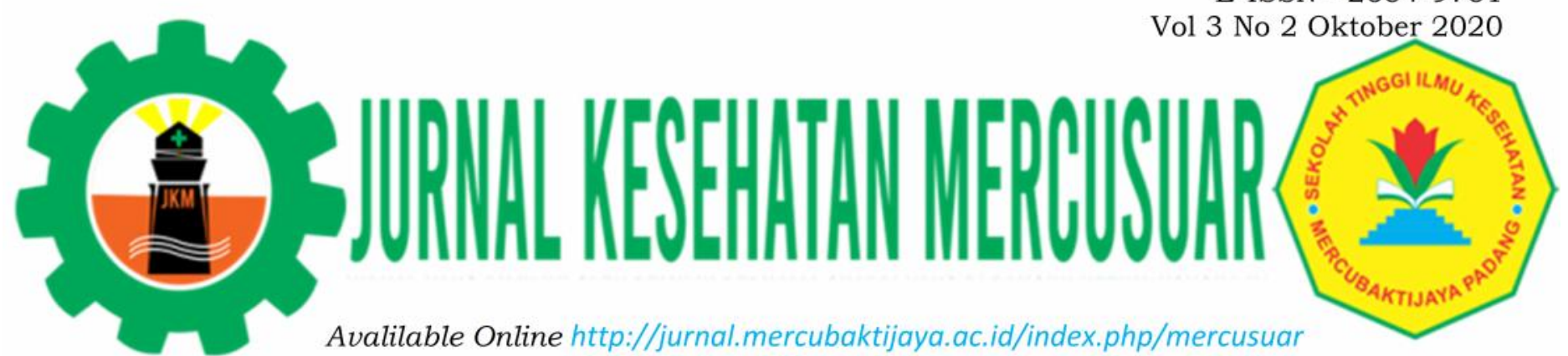

\title{
ASESMEN TINGKAT KEPUASAN DAN PERSEPSI ASUHAN ANTENATAL PADA IBU - IBU TUNANETRA DI KOTA PADANG (STUDI KASUS)
}

\author{
Sunesni $^{1 *}$, Dian Furwasyih ${ }^{2}$ \\ 12Program Studi Kebidanan Program Sarjana dan Program Studi Pendidikan Bidan Program \\ Profesi, STIKes MERCUBAKTIJAYA PADANG \\ *Email:nesni_harfi@yahoo.co.id
}

\begin{abstract}
The International Agency for The Prevention of Blindness states that two thirds of blind people in the world are women. This group made very few antenatal visits. This results in poor maternal and infant well-being and pregnancy outcomes when compared to the general population. In addition, health workers are often incompetent in providing services to this group, thus rendering the antenatal services provided of poor quality. This study aims to assess the level of satisfaction and perceptions of blind pregnant women on antenatal care in Padang city. The study design was a descriptive study with cross sectional approach. The research informants were 16 people. The results showed that $12.5 \%$ of informants expressed dissatisfaction with antenatal care and 54\% expressed negative perceptions of antenatal care. The discriminatory treatment and communication of officers that are difficult to understand, and the unavailability of special disability lines at the service counters are some of the complaints raised by informants during interviews.

It can be concluded that a small proportion of informants were dissatisfied with the pregnancy services obtained and more than half of the informants had a negative perception of the pregnancy services obtained. It is recommended that the government and the private sector place the issue of health services on groups with special needs as one of the priority programs in the health sector so as to ensure social and health protection for this group.
\end{abstract}

\section{Kata Kunci :}

pregnant women, visual impairment, people with disability, perception, antenatal care 
Abstrak

International Agency for The Prevention of Blindness menyatakan dua pertiga dari penyandang tuna netra di dunia adalah perempuan. Kelompok ini sangat jarang melakukan kunjungan antenatal. Hal ini mengakibatkan buruknya kesejahteraan ibu dan bayi serta outcome kehamilan jika dibandingkan dengan populasi pada umumnya. Selain itu, seringkali tenaga kesehatan tidak kompeten dalam memberikan pelayanan pada kelompok ini sehingga menjadikan pelayanan antenatal yang diberikan tidak berkualitas. Penelitian ini bertujuan mengkaji tingkat kepuasan dan persepsi ibu hamil tunanetra terhadap pelayanan antenatal di Kota Padang. Desain penelitian adalah deskriptif observasional dengan pendekatan potong lintang. Informan penelitian berjumlah 16 orang. Hasil penelitian mengungkapkan bahwa 12,5\% informan menyatakan tidak puas terhadap pelayanan antenatal dan 54\% menyatakan persepsi negatif terhadap pelayanan antenatal. Perlakuan diskriminatif dan komunikasi petugas yang sulit dipahami, serta tidak tersedianya jalur khusus disabilitas pada konter pelayanan merupakan beberapa keluhan yang dikemukakan informan saat wawancara.

Dapat disimpulkan bahwa sebagian kecil informan merasa tidak puas terhadap pelayanan kehamilan yang didapatkan dan lebih dari separuh informan mempunyai persepsi negatif terhadap pelayanan kehamilan yang diperoleh. Disarankan pada pemerintah dan swasta untuk menempatkan isu pelayanan kesehatan pada kelompok berkebutuhan khusus sebagai salah satu program prioritas bidang kesehatan sehingga menjamin perlindungan sosial dan kesehatan pada kelompok ini.

\section{Kata Kunci :}

ibu hamil, tunanetra, penyandang disabilitas, persepsi, pelayanan antenatal

\section{PENDAHULUAN}

Tuna netra atau buta menempati urutan tertinggi untuk penyandang disabilitas di Indonesia. Jumlahnya mencapai 3,5 juta jiwa pada tahun 2015. (Damayanti, 2015). Menurut International Agency for The Prevention of Blindness, dua pertiga dari penyandang tuna netra adalah perempuan. (Persatuan Tunanetra Indonesia, 2017).

Perempuan tunanetra sering kali terpinggirkan dan dianggap sebagai komunitas yang tidak penting jika dibandingkan dengan kelompok lelaki tunanetra. Perempuan tunanetra juga lebih sering mengalami diskriminasi dibandingkan dengan kelompok lelaki tunanetra. Perempuan tunanetra lebih sulit mengakses pendidikan, pelayanan kesehatan yang terjangkau, kesempatan bekerja, dan mengalami isolasi dengan rasio lebih tinggi dibandingkan dengan kelompok lelaki tuna netra. (Persatuan Tunanetra Indonesia, 2017)
Dari penelitian yang dilakukan Homeyard (2016) didapatkan hasil bahwa perempuan dengan disabilitas sangat jarang mengunjungi fasilitas kesehatan. Hal ini pun terjadi ketika hamil. Perempuan dengan disabilitas juga sangat jarang melakukan kunjungan antenatal. Hal ini mengakibatkan buruknya kesejahteraan ibu dan bayi serta outcome kehamilan jika dibandingkan dengan populasi pada umumnya, termasuk lebih sering mengalami prematur dan bayi dengan berat lahir rendah. (Homeyard, Montgomery, Chinn, \& Patelarou, 2016)

Stigma yang berkembang di masyarakat tentang ketidakmampuan perempuan tunanetra untuk menjadi seorang ibu, menyebabkan perempuan tuna netra enggan untuk melakukan kunjungan antenatal ketika hamil. Selain itu, seringkali tenaga kesehatan tidak mempunyai kompetensi yang adekuat untuk memberikan pelayanan antenatal kepada perempuan tuna netra. Masalah dalam berkomunikasi ketika memberikan 
pendidikan kesehatan tentang kehamilan menjadikan pelayanan antenatal tidak berkualitas. (Malouf, Henderson, \& Redshaw, 2017)

Bidan sebagai salah satu profesional kesehatan yang sangat dekat dengan perempuan, seharusnya mampu menjawab tantangan - tantangan diatas. Bidan dalam konteks sosial harus mempunyai kecakapan dalam memberikan pelayanan pada kelompok perempuan yang termarginalisasi seperti ibu - ibu muda, perempuan disabilitas, kelompok lesbian, dan pekerja seks komersil. Bidan harus mempunyai kemampuan komunikasi yang baik sehingga dapat membangun kepercayaan dan hubungan baik dengan klien. (Diane $\mathrm{M}$. Fraser; Margareth A. Cooper, 2009)

Dari tahun ke tahun, jumlah perempuan disabilitas yang menjadi ibu terus meningkat, akan tetapi studi tentang akses dan pengalaman mereka selama kehamilan, persalinan, dan masa nifas sangat jarang dilakukan. (Malouf et al., 2017). Hal yang sama terjadi juga di Indonesia. Terbukti dengan belum adanya artikel publikasi yang membahas masalah akses pelayanan antenatal bagi perempuan disabilitas khususnya tunanetra di Indonesia.

Di kota Padang sendiri, penulis tidak menemukan data pasti angka perempuan tuna netra yang hamil ataupun yang mempunyai balita. Data - data yang tersedia di website dinas sosial maupun dinas kesehatan tidak mempunyai pembahasan khusus tentang akses pelayanan kesehatan bagi perempuan tuna netra yang hamil, bersalin, maupun mempunyai bayi dan balita. Padahal, kelompok ini mempunyai proporsi yang cukup besar untuk berkontribusi pada outcome kehamilan yang tidak optimal seperti disebutkan diatas jika semasa kehamilan mereka tidak mendapatkan akses ke pelayanan antenatal yang berkualitas dan tidak sejahtera secara fisik dan emosional.
Oleh sebab itu, penulis tertarik untuk melakukan asesmen tentang persepsi dan pengalaman perempuan tuna netra di kota Padang terhadap pelayanan antenatal yang mereka terima selama menjalani kehamilan.

\section{METODE PENELITIAN}

Jenis penelitian adalah penelitian deskriptif kualitatif dengan pendekatan cross sectional yang menggambarkan persepsi dan pengalaman ibu - ibu tuna netra tentang pelayanan antenatal yang diterima selama hamil. Informan penelitian adalah ibu - ibu tuna netra yang sedang hamil atau pernah melahirkan (16 orang). Pengumpulan data dilakukan dengan metode wawancara menggunakan daftar pertanyaan. Dalam penelitian ini penulis melibatkan 4 (empat) orang mahasiswa yang membantu mengumpulkan data dan melakukan wawancara pada para informan. Tiap wawancara direkam menggunakan perekam suara dari telepon seluler dan ditranskripsi sesuai dengan hasil percakapan selama wawancara.

Data yang dikumpulkan dianalisis dengan aplikasi NVIVO QSR 10 dan MS Office Excel 2013. Data dianalisis berdasarkan pernyataan informan tentang persepsi dan pengalaman pelayanan antenatal yang diterima selama hamil. Pernyataan diklasifikasikan pada 3 klasifikasi yaitu positif, negatif, dan tidak dapat mengevaluasi.

\section{HASIL PENELITIAN}

Jumlah informan yang di wawancara dalam pengumpulan data adalah 16 orang. Pada tabel di bawah ini dirincikan karakteristik informan berdasarkan usia, paritas, tingkat pendidikan, pekerjaan, penghasilan, dan kepemilikan buku KIA 


\section{A. Tabel 1 Gambaran Umum Informan Penelitian}

\begin{tabular}{|c|c|c|c|}
\hline Kategori & $\mathrm{n}$ & $\%$ & Ket \\
\hline \multicolumn{4}{|l|}{ Usia } \\
\hline $31-35$ & 5 & $31.25 \%$ & \\
\hline $36-40$ & 6 & $37.5 \%$ & \\
\hline$>40$ & 5 & $31.25 \%$ & \\
\hline \multicolumn{4}{|l|}{ Paritas } \\
\hline Primipara & 4 & $25 \%$ & \\
\hline Multipara & 12 & $75 \%$ & \\
\hline \multicolumn{4}{|l|}{ Usia anak terkecil } \\
\hline $1-5$ tahun & 11 & $68.75 \%$ & \\
\hline $6-10$ tahun & 2 & $12.5 \%$ & \\
\hline$>10$ tahun & 3 & $18.75 \%$ & \\
\hline \multicolumn{4}{|c|}{ Tingkat pendidikan } \\
\hline Rendah & 14 & $87.5 \%$ & \\
\hline Menengah & 2 & $12.5 \%$ & \\
\hline Tinggi & 0 & 0 & \\
\hline \multicolumn{4}{|l|}{ Pekerjaan } \\
\hline IRT & 1 & $6.25 \%$ & \\
\hline Pijat & 14 & $87.5 \%$ & \\
\hline Lain - lain & 1 & $6.25 \%$ & Pengemis \\
\hline \multicolumn{3}{|l|}{ Status ekonomi } & \multirow{3}{*}{$\begin{array}{l}\text { Status ekonomi dibandingkan dengan UMP } \\
\text { tahun } 2019 \text { yaitu sebesar } 2,28 \text { juta }\end{array}$} \\
\hline Tidak Baik & 14 & $87.5 \%$ & \\
\hline Baik & 2 & $12.5 \%$ & \\
\hline \multicolumn{4}{|c|}{ Kepemilikan buku KIA } \\
\hline Ada & 3 & $18.75 \%$ & \\
\hline Tidak ada & 13 & $81.25 \%$ & Hilang karna banjir (1 orang) \\
\hline Total & 16 & $100 \%$ & \\
\hline
\end{tabular}

Tabel 1 menunjukkan bahwa hampir $40 \%$ informan berada pada kelompok usia $36-40$ tahun. Sebagian besar informan adalah multipara (75\%), usia anak terkecil pada kelompok umur 1 - 5 tahun (68,75\%). Hasil penelitian kami juga mengungkapkan bahwa 14 orang informan mempunyai level pendidikan rendah, dan dari 14 orang ini, 12 


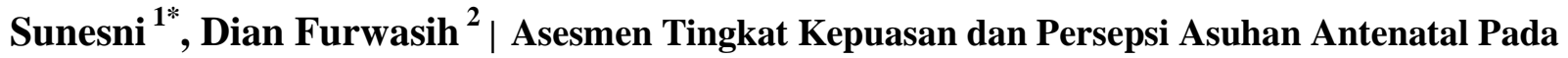
Ibu-Ibu Tunanetra di Kota Padang

orang hanya mendapatkan pendidikan setingkat SDLB dan sekolah pijat. Jenis pekerjaan dari informan sebagian besar $(87,5 \%)$ merupakan tukang pijat. Ada 1 orang informan yang bekerja sebagai pengemis. Dilihat dari kepemilikan buku KIA, investigasi kami mengungkapkan bahwa hanya 3 orang $(18,75 \%)$ informan yang mempunyai buku KIA.

Tabel 2 Analisis Kualitatif Persepsi Ibu Tunanetra Tentang Pelayanan Antenatal

\begin{tabular}{|c|c|c|c|c|}
\hline \multirow[t]{2}{*}{ No } & \multirow{2}{*}{$\begin{array}{c}\text { Nomor } \\
\text { Pertanyaan }\end{array}$} & \multicolumn{3}{|c|}{ Kategori } \\
\hline & & Puas & Cukup puas & Tidak puas \\
\hline 1 & Q.4 & 12 & 2 & 2 \\
\hline & & $\begin{array}{l}\text { Baik, dari segi } \\
\text { pelayanan dan } \\
\text { fasilitasnya bagus dan } \\
\text { saya berobat dan suntik } \\
\text { kb saya gratis di tempat } \\
\text { bidan tersebut. } \\
\text { Transkrip } \mathbf{1 4} \mathbf{N y} . \mathbf{N}\end{array}$ & $\begin{array}{l}\text { Merasa cukup puas } \\
\text { dengan } \\
\text { pelayanannya. } \\
\text { Transkrip } 6 \mathbf{N y} . \mathbf{N}\end{array}$ & $\begin{array}{l}\text { Insyaallah baik, tapi pas } \\
\text { kelahiran anak ke } 3 \\
\text { agak kecewa pas satu } \\
\text { hari melahirkan udah di } \\
\text { suruh pulang. kata } \\
\text { dokter anak saya } \\
\text { tersebut terminum air } \\
\text { ketuban dan tidak } \\
\text { disedot sehingga anak } \\
\text { saya meninggal. karena } \\
\text { kamar penuh dan dikira } \\
\text { saya pakai BPJS } \\
\text { padahal saya bayar } \\
\text { umum bukan pakai } \\
\text { BPJS. Transkrip } \mathbf{1 5} \mathbf{N y .} \\
\mathbf{U}\end{array}$ \\
\hline
\end{tabular}

\begin{tabular}{|c|c|c|c|c|}
\hline \multirow[t]{2}{*}{ No } & \multirow{2}{*}{$\begin{array}{c}\text { Nomor } \\
\text { Pertanyaan }\end{array}$} & \multicolumn{3}{|c|}{ Kategori } \\
\hline & & Positif & Negatif & $\begin{array}{c}\text { Tidak memberikan } \\
\text { jawaban }\end{array}$ \\
\hline \multirow[t]{2}{*}{2} & Q9 & 6 & 7 & 3 \\
\hline & & $\begin{array}{c}\text { Aman dan tidak ada } \\
\text { kendala Transkrip } 16 \\
\text { Ny. Y }\end{array}$ & $\begin{array}{l}\text { Kalau dapat bidan } \\
\text { atau dokter gak } \\
\text { membedakan antara } \\
\text { tuna netra dan } \\
\text { melihat pada }\end{array}$ & - \\
\hline
\end{tabular}


umumnya kan tuna

netra itu kan sama,

sama sama

perempuan juga.

Transkrip 15 Ny. U

Pengalaman saya

pribadi, tenaga

kesehatannya ramah,

namun ada beberapa

teman saya yang

mendapatkan

perlakuan kasar dari

tenaga kesehatan.

Transkrip 9 Ny. R

Tabel 2 menjelaskan hasil analisis kualitatif dari wawancara tentang persepsi pemberian asuhan antenatal pada ibu tunanetra di Kota Padang. Tulisan yang dimiringkan merupakan gambaran respon atau jawaban dari informan ketika pertanyaan tersebut dilontarkan saat wawancara.

Pada pertanyaan tentang tingkat kepuasan informan terhadap pelayanan antenatal yang didapatkan, respon informan diklasifikasikan pada 3 kategori, yaitu puas, cukup puas, dan tidak puas. Selanjutnya, pada pertanyaan tentang persepsi pasien, respon dari informan dikategorikan pada 3 kategori juga yaitu positif, negatif, dan tidak memberikan jawaban. Terlihat pada tabel 2 sebagian besar informan (75\%) menyatakan puas dengan pelayanan yang didapatkan selama hamil di fasilitas kesehatan di Kota Padang. Seperti diungkapkan oleh Ny. N (kode informan 14) sebagai berikut :

“Baik, dari segi pelayanan......”.
Pada tabel 2 juga terlihat ada 2 orang responden yang merasa tidak puas dengan pelayanan antenatal yang diterima selama hamil. Seperti diungkapkan oleh Ny. U (kode informan 15) sebagai berikut :

"Insyaallah baik, tapi pas kelahiran anak ke 3 agak kecewa pas satu hari melahirkan udah di suruh pulang. kata dokter anak saya tersebut terminum air ketuban dan tidak disedot sehingga anak saya meninggal. karena kamar penuh dan dikira saya pakai BPJS padahal saya bayar umum bukan pakai BPJS."

Pertanyaan 4 dan 9 kemudian di elaborasi dengan pertanyaan poin 10 yaitu saran perbaikan terhadap pelayanan kesehatan antenatal pada pasien tunanetra. Ada beberapa poin yang disorot oleh informan, rincian dari hasil wawancara ini dirangkum pada tabel 3 : 
Tabel 3 Saran Perbaikan Informan terhadap Pelayanan Antenatal Ibu Tunanetra di Kota Padang

: Apa saran perbaikan ibu untuk pelayanan antenatal pada ibu tunanetra di Kota Padang?

\begin{tabular}{|c|c|c|c|}
\hline No & Saran & & Cuplikan Respon Informan \\
\hline 1 & $\begin{array}{l}\text { Penyediaan jalur } \\
\text { khusus tunanetra }\end{array}$ & $7 / 14$ & $\begin{array}{l}\text { Hendaknya adanya jalur khusus untuk tunanetra, atau } \\
\text { rambu-rambu khusus bagi tunanetra agar memudahkan } \\
\text { tunanetra mencapai tempat pelayanan kesehatan yang } \\
\text { dituju.... } \\
\text { (Informan } 9 \mathrm{Ny} . \mathrm{R} \text { ) }\end{array}$ \\
\hline 2 & $\begin{array}{l}\text { Komunikasi } \\
\text { petugas }\end{array}$ & $3 / 14$ & $\begin{array}{l}\text { Cara komunikasi tenaga kesehatan mungkin lebih } \\
\text { diperbaiki, karena waktu dirumah sakit, pernah dibilang } \\
\text { kalau ibu tunanetra itu melahirkan harus operasi tidak bisa } \\
\text { normal, padahal saya sendiri kemarin melahirkan secara } \\
\text { normal. } \\
\text { (Informan } 10 \mathrm{Ny} . \mathrm{E})\end{array}$ \\
\hline 3 & Akses informasi & $10 / 14$ & $\begin{array}{l}\text { Kalau dapat selama hamil sebaiknya dijelaskan lebih jelas } \\
\text { agar kami bisa mendapatkan lebih jelas informasinya } \\
\text { (Informan } 14 \mathrm{Ny} . \mathrm{N} \text { ) }\end{array}$ \\
\hline 4 & $\begin{array}{l}\text { Media pengganti } \\
\text { buku KIA }\end{array}$ & $12 / 14$ & $\begin{array}{l}\text { Adanya media pengganti buku KIA, karena tunanetra tidak } \\
\text { bisa memanfaatkan buku tersebut secara maksimal } \\
\text { (Informan } 11 \mathrm{Ny} . \mathrm{M} \text { ) }\end{array}$ \\
\hline 5 & $\begin{array}{l}\text { Pendampingan } \\
\text { nakes saat } \\
\text { berkunjung ke } \\
\text { faskes }\end{array}$ & $10 / 14$ & $\begin{array}{l}\text { Sebaiknya ada petugas khusus pendamping ibu-ibu buta } \\
\text { saat ke puskesmas jadi tidak susah } \\
\text { (Informan } 4 \mathrm{Ny} \text {. L) }\end{array}$ \\
\hline
\end{tabular}

Tabel 3 mengungkapkan beberapa isu utama yang menjadi sorotan para informan ketika mengakses pelayanan kehamilan. Dari 16 informan, 2 orang tidak memberikan respon pada pertanyaan ini. Terlihat bahwa ada 5 tema yang menjadi fokus pembahasan informan penelitian yaitu penyediaan jalur khusus tunanetra, komunikasi petugas, akses informasi, media pengganti buku KIA, dan pendampingan tenaga kesehatan saat berkunjung ke fasilitas kesehatan.

\section{PEMBAHASAN}

Secara umum, perempuan tunanetra memberikan respon yang baik terhadap pertanyaan tentang tingkat kepuasan mereka ketika mendapatkan pelayanan antenatal di fasilitas pelayanan kesehatan, meskipun demikian ada $12,5 \%$ informan menyatakan hal sebaliknya. Hasil penelitian ini sejalan dengan penelitian Hall et.al yang mengungkapkan bahwa sebagian informan menyatakan tidak memperoleh pelayanan yang semestinya ketika mereka mengunjungi fasilitas kesehatan. Informan mengemukakan bahwa mereka merasa hak hak mereka tidak sepenuhnya dihargai dan tidak diberikan pelayanan selayaknya karena kecacatan yang mereka alami. (Hall, Hundley, Collins, \& Ireland, 2018).

Respon informan pada pertanyaan tentang persepsi pasien dikategorikan pada 3 kategori juga yaitu positif, negatif, dan tidak memberikan jawaban. Tiga (3) orang informan tidak memberikan respon terhadap pertanyaan ini, sedangkan hampir 54\% mengungkapkan persepsi negatif terhadap 
pelayanan antenatal yang mereka dapatkan. Salah satunya terlihat pada jawaban dari Ny. U yang mengemukakan seperti berikut ini :

"Kalau dapat bidan atau dokter gak membedakan antara tuna netra dan melihat pada umumnya kan tuna netra itu kan sama, sama sama perempuan juga."

Ibu merasakan adanya perbedaan perlakuan terhadap dirinya ketika mendapatkan pelayanan antenatal di fasilitas pelayanan kesehatan. Pada tabel 3 kita dapat melihat beberapa isu yang menjadi keluhan dari ibu tunanetra ketika mengunjungi tenaga kesehatan untuk pemeriksaan kehamilan.

Tidak adanya media edukasi pengganti buku KIA yang tersedia di fasilitas pelayanan kehamilan menjadi penyebab utama ketidakpuasan informan, seperti diungkapkan oleh 12 dari 14 orang informan.

“...........karena tunanetra tidak bisa memanfaatkan buku (KIA) tersebut secara maksimal” (Informan 11 Ny. M)

Buku KIA merupakan buku yang berisikan informasi kesehatan bagi ibu hamil, bersalin, nifas, bayi, balita dan anak. Buku ini juga merupakan alat komunikasi antar tenaga kesehatan ketika melakukan pelayanan kesehatan pada ibu sepanjang siklus reproduksi. Saat ini, belum tersedia buku KIA yang bisa diakses dengan mudah oleh ibu tunanetra sehingga hal ini menyulitkan mereka untuk mendapatkan informasi yang cukup ketika menjalani kehamilan, persalinan, maupun masa nifas dan merawat anak. Oleh sebab itu, perlu adanya media edukasi pengganti buku KIA yang dapat diakses oleh ibu tunanetra sehingga ibu dapat menjalani masa kehamilan dengan lebih baik dan menghasilkan outcome kelahiran yang lebih optimal.

Informan $14 \mathrm{Ny}$. N mengungkapkan :

"Kalau dapat selama hamil sebaiknya dijelaskan lebih jelas agar kami bisa mendapatkan lebih jelas informasinya"

Pemberian informasi yang tidak adekuat juga menjadi hal yang dikeluhkan oleh informan. Menurut informan, cara berkomunikasi dari tenaga kesehatan tidak memperhatikan kebutuhan mereka. Seperti diungkapkan oleh informan 10 Ny. E dibawah ini :

"Cara komunikasi tenaga kesehatan mungkin lebih diperbaiki, karena waktu dirumah sakit, pernah dibilang kalau ibu tunanetra itu melahirkan harus operasi tidak bisa normal, padahal saya sendiri kemarin melahirkan secara normal."

Sebagian perempuan dengan disabilitas merasa kesulitan dalam mencari petugas kesehatan yang memiliki pengalaman memberikan pelayanan kepada perempuan disabilitas sehingga tenaga kesehatan yang mereka kunjungi tidak bisa memberikan pelayanan sesuai dengan kebutuhan mereka. Hal ini diungkapkan di dalam hasil penelitian (Akasreku, Habib, \& Ankomah, 2018; Debus, 2015). Ibu dengan disabilitas mengungkapkan bahwa tenaga kesehatan cenderung tidak memberi dukungan yang cukup ketika memberikan pelayanan kesehatan kepada mereka selama hamil. Informasi yang disampaikan terkesan menakut - nakuti. Seperti respon Ny E diatas yang diberi informasi bahwa perempuan tunanetra harus bersalin dengan operasi. Hal ini juga diungkapkan oleh responden pada penelitian Debus (2015), sebagian perempuan disabilitas mengalami persalinan dengan seksio sesaria meskipun 
pilihan persalinan mereka adalah persalinan pervaginam.

Responden Debus (2015) juga menyampaikan bahwa kelas antenatal tidak informatif dan tidak membantu ibu mempersiapkan kehamilan. Hal ini disebabkan instruktur di kelas tersebut tidak mempunyai pengetahuan yang cukup tentang disabilitas yang mereka alami dan pengaruh dari disabilitas tersebut terhadap kehamilan ibu. (Debus, 2015)

Ketidakpercayaan diri yang terbentuk dari akibat pemberian informasi yang salah saat konseling antenatal, berakibat pada kekhawatiran berlebihan saat menjalani kehamilan. Perempuan dengan disabilitas cendrung takut untuk mencari pertolongan tenaga medis ketika merasakan adanya keluhan selama masa reproduksinya. Respon pertama kali yang diungkapkan oleh tenaga kesehatan adalah berupa rasa tidak percaya bahwa perempuan tunanetra tidak bisa menjalani kehamilan dengan baik, perempuan tunanetra harus menggugurkan kandungannya, dan berbagai reaksi negatif lainnya. (Debus, 2015)

Tenaga kesehatan harus memahami metode konseling yang tepat pada kelompok ibu disabilitas. Informasi tentang seberapa berdampak disabilitas yang mereka alami terhadap proses reproduksi mereka menjadi hal yang krusial untuk disampaikan dalam kelas antenatal dan persiapan menjadi orang tua, sehingga menurunkan risiko outcome kehamilan dengan kualitas yang buruk. Kolaborasi multidisiplin juga sangat penting jika ibu masih mengonsumsi obat - obatan tertentu terkait dengan disabilitas yang dialami dengan mempertimbangkan risiko pemberian obat terhadap janin. Memastikan bahwa setiap ibu dengan disabilitas terbebas dari respon negatif tenaga kesehatan baik verbal maupun non verbal juga harus menjadi perhatian utama dari fasilitas pelayanan kesehatan sehingga ibu dengan disabilitas mendapat pelayanan kesehatan yang setara dengan sesama perempuan lain.

Tujuh (7) dari 14 orang informan mengungkapkan tidak tersedianya jalur khusus bagi tunanetra di fasilitas pelayanan kesehatan menyulitkan akses bagi mereka menuju konter pelayanan yang diinginkan. Kemudian, tidak tersedianya tenaga kesehatan khusus pendamping ibu tunanetra di fasilitas pelayanan kesehatan menjadi masalah tersendiri yang juga harus dibahas lebih lanjut. Hal ini diungkapkan oleh Ny. R dan Ny. L seperti berikut :

"Hendaknya adanya jalur khusus untuk tunanetra, atau rambu-rambu khusus bagi tunanetra agar memudahkan tunanetra mencapai tempat pelayanan kesehatan yang dituju...” (Ny. R)

"Sebaiknya ada petugas khusus pendamping ibu - ibu buta saat ke puskesmas jadi tidak susah" (Ny. L)

Jalur khusus disabilitas dengan gangguan penglihatan menjadi penting untuk memudahkan mobilitas mereka pada fasilitas pelayanan publik. Begitu pula dengan ibu tunanetra. Studi kami mengungkapkan bahwa sebagian (50\%) informan mengeluhkan tidak adanya jalur khusus untuk ibu tunanetra menuju konter pelayanan yang diinginkan. Hal ini diperburuk dengan tidak adanya tenaga kesehatan yang mendampingi mereka di fasilitas pelayanan kesehatan. Di beberapa negara, telah disediakan aplikasi navigasi untuk orang dengan gangguan penglihatan seperti landmark-enhanced route yang digunakan untuk pejalan kaki dengan kebutaan. Aplikasi ini sangat efektif bagi pejalan kaki tunanetra untuk menemukan 
area yang ingin dikunjungi. (Balata, Mikovec, \& Slavik, 2018). Aplikasi serupa dapat dimodifikasi untuk kebutuhan ibu dengan tunanetra ketika harus melakukan kunjungan selama kehamilan ke fasilitas pelayanan kesehatan.

\section{SIMPULAN DAN SARAN}

Sebagian kecil (12,5\%) informan menyatakan tidak puas terhadap pelayanan kehamilan yang didapatkan di fasilitas kesehatan. Hal ini terutama disebabkan oleh tidak adanya media pengganti buku KIA untuk ibu tunanetra, cara berkomunikasi tenaga kesehatan yang tidak informatif, informasi yang disampaikan tidak menjawab kebutuhan ibu tunanetra, tidak ada tenaga kesehatan pendamping khusus ibu tunanetra, dan tidak adanya jalur khusus bagi ibu tunanetra untuk mencapai konter pelayanan yang diinginkan. Lebih dari separuh (54\%) informan mempunyai persepsi negatif terhadap pelayanan kehamilan yang diperoleh.

Pengadaan buku pemantauan kesehatan khusus bagi ibu tunanetra adalah satu hal yang harus menjadi prioritas, sebab dengan adanya buku tersebut maka ibu tunanetra dapat mengakses informasi kesehatan seputar masa reproduksi. Edukasi kesehatan yang efektif akan meningkatkan tingkat pengetahuan ibu sehingga diharapkan outcome kelahiran yang lebih baik. Selain itu, cara berkomunikasi dan pemberian informasi yang jelas pada ibu tunanetra juga penting untuk menjadi perhatian, sehingga mereka mendapatkan informasi yang sama dengan ibu yang normal. Kemudian, pengadaan jalur khusus bagi ibu tunanetra di fasilitas pelayanan juga perlu dipertimbangkan, sehingga terwujud fasilitas pelayanan kesehatan yang inklusif atau ramah disabilitas.

\section{DAFTAR PUSTAKA}

Akasreku, B. Dela, Habib, H., \& Ankomah, A. (2018). Pregnancy in Disability: Community Perceptions and Personal Experiences in a Rural Setting in Ghana. Journal of Pregnancy, 2018, $1-12$.

https://doi.org/10.1155/2018/8096839

Balata, J., Mikovec, Z., \& Slavik, P. (2018). Landmark-enhanced route itineraries for navigation of blind pedestrians in urban environment. Journal on Multimodal User Interfaces, 12(3), 181-198. https://doi.org/10.1007/s12193-0180263-5

Damayanti, I. (2015). 3,5 Juta Tunanetra Perlu Diberdayakan. Retrieved May 5, 2019, from Koran SINDO website: https://nasional.sindonews.com/read/9 49940/149/35-juta-tunanetra-perludiberdayakan-1421133129

Debus, G. (2015). Pregnancy in women with disabilities. Gynakologe, 48(11), 843-848.

https://doi.org/10.1007/s00129-0153799-4

Diane M. Fraser; Margareth A. Cooper. (2009). Section 1 The Midwife. In Diane M. Fraser; Margaret A. Cooper (Ed.), Myles Fifteenth Edition, Textbook for Midwives (15th ed.). Toronto, Canada: Churchill Livingstone Elsevier.

Hall, J., Hundley, V., Collins, B., \& Ireland, J. (2018). Dignity and respect during pregnancy and childbirth: A survey of the experience of disabled women. BMC Pregnancy and Childbirth, 18(1), 1-13. https://doi.org/10.1186/s12884-0181950-7

Homeyard, C., Montgomery, E., Chinn, D., \& Patelarou, E. (2016). Current evidence on antenatal care provision 


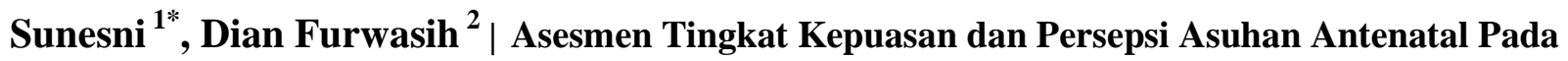
Ibu-Ibu Tunanetra di Kota Padang

for women with intellectual

disabilities: A systematic review.

Midwifery, 32, 45-57.

https://doi.org/10.1016/j.midw.2015.1 0.002

Malouf, R., Henderson, J., \& Redshaw, M. (2017). Access and quality of maternity care for disabled women during pregnancy, birth and the postnatal period in England: data from a national survey. BMJ Open, 7(7), e016757.

https://doi.org/10.1136/bmjopen-2017016757

Persatuan Tunanetra Indonesia. (2017).

Press Relese: International Women's Day 2017 | Pertuni. Retrieved May 5, 2019, from PERTUNI website:

http://pertuni.or.id/press-relese-

international-womens-day-2017/ 